\title{
The Manitoba Association of Health Information Providers (MAHIP)
}

The Manitoba Association of Health Information Providers (MAHIP) was very active in 2012-2013.

Three journal clubs were held in 2012-2013. A critical appraisal checklist was utilized to assist in appraising articles and guiding discussion (Glynn L. A critical appraisal tool for library and information research. Library Hi Tech. 2006; 24(3): 387-399). In 2013-2014 we will continue to evaluate the process of journal club facilitation, implement an evaluation form, and review additional journal club facilitation guidelines.

Since 2010, library associations in Manitoba have been assessing the current structure of library associations and determining support for the creation of an umbrella library organization. MAHIP held a members meeting on 19 September 2012 to discuss MAHIP's potential involvement in such an association. MAHIP's President and VicePresident attended three meetings of the Manitoba Library Associations Working Group. A sub-committee of the Working Group was created to draft an organizational structure reflecting the needs of all participating associations. Results from the sub-committee are still pending.

In 2012, Ada Ducas, Kerry Macdonald, and Lisa Demczuk received CHLA/ABSC's Chapter Initiatives Grant for their research on "Benchmarking Canadian Health Facility Libraries". Their research is now complete and they presented their findings at the 2013 CHLA/ABSC conference in Saskatoon. Their final report is available at: http://www.chla-absc.ca/system/files/MAHIP_CIF_final report.doc

A MAHIP member's meeting was held on 3 April 2013 to consult on proposed amendments to MAHIP's constitution. Amendments were voted on and accepted at the Annual General Meeting, and they included: adding a retired member option, clarifying voting rights of institutional members, adding the position of Past President, and extending the terms of Secretary and Treasurer from oneyear to two-year terms.

MAHIP's Annual General Meeting was held on 18 June 2013. The new executive for 2013-2014 include: Orvie Dingwall, President; Mê-Linh Lê, Vice President; Andrea Szwajcer, Past President; Sherri Vokey, Treasurer; and Caroline Monnin, Secretary.

MAHIP has a new website at www.chla-absc.ca/mahip thanks to MAHIP's webmasters Christine Shaw-Daigle and Melissa Raynard who migrated the website from WordPress.

\section{Orvie Dingwall}

MAHIP President

MHIKNET Librarian

Neil John Maclean Health Sciences Library

University of Manitoba

E-mail: orvie_dingwall@umanitoba.ca

Andrea Szwajcer

MAHIP Past President

Clinical Librarian

Carolyn Sifton-Helene Fuld Library

St. Boniface Hospital

University of Manitoba

E-mail: andrea.szwajcer@umanitoba.ca 